\title{
Managing Severe Tetanus without Ventilation Support in a Resource-limited Setting in Bangladesh
}

\author{
Md Golam Hasnain, ${ }^{1,2 *} \dagger$ Shomik Maruf, ${ }^{2} \dagger$ Proggananda Nath, ${ }^{3}$ Azim Anuwarul, ${ }^{3}$ Md Nasir Uddin Ahmed, ${ }^{3}$ \\ lqbal Hossain Chowdhury, ${ }^{4}$ and Ariful Basher ${ }^{5}$ \\ ${ }^{1}$ Centre for Clinical Epidemiology and Biostatistics (CCEB), School of Medicine and Public Health (SMPH), Faculty of Health and Medicine, The \\ University of Newcastle, Callaghan, New South Wales, Australia; ${ }^{2}$ Nutrition and Clinical Service Division (NCSD), International Centre for Diarrhoeal \\ Disease Research, Bangladesh (icddr,b), Dhaka, Bangladesh; ${ }^{3}$ Infection and Tropical Medicine, Mymensingh Medical College and Hospital \\ $(\mathrm{MMCH})$, Mymensingh, Bangladesh; ${ }^{4}$ Department of Intensive Care Unit, Bangabondhu Sheikh Mujib Medical University (BSMMU), Dhaka, \\ Bangladesh; ${ }^{5}$ Critical Care Medicine (CCM), Bangabondhu Sheikh Mujib Medical University (BSMMU), Dhaka, Bangladesh
}

\begin{abstract}
Tetanus, a vaccine-preventable and potentially fatal disease, continues to remain prevalent in low- and middle-income countries. Furthermore, physicians are often unfamiliar with management of severe tetanus without ventilator support. Therefore, we proposed a modified treatment protocol that provides a low-cost and effective solution for the management of severe tetanus in resource-constrained settings. This is an observational study of 42 patients with severe tetanus treated during 2015-2016 at Surya Kanta Hospital, Bangladesh. This facility does not have an intensive care unit (ICU), and patients admitted here were provided treatment with the modified protocol. A total number of 42 patients with severe tetanus were treated with the modified protocol. Among them, $24(57.1 \%)$ recovered completely, six $(14.3 \%)$ recovered with the sequela, and 12 (28.6\%) died. Among those who recovered with the sequela, four needed mechanical support during walking and two had a visual impairment. No significant adverse event was recorded during the treatment period. The results gathered during this case series provide a sustainable, low-cost, and effective solution to management of severe tetanus in resource-constrained settings where ICUs are unavailable.
\end{abstract}

\section{INTRODUCTION}

Tetanus, a vaccine-preventable disease, continues to remain prevalent in low- and middle-income countries ${ }^{1-4}$ with a high rate of mortality and morbidity. Despite having a drastic reduction in tetanus cases, and its related mortality, the world is still suffering with a considerable number of cases. In 2015, a total of 56,743 tetanus-related deaths were reported and among them 36,806 cases were non-neonatal with concentrated reports from South Asian and sub-Saharan countries. ${ }^{5}$ Tetanus is a painful disease caused by a neurotoxin released from wounds infected with Clostridium tetani and is characterized by increased muscle tone, and spasm which leads to cardiovascular instability, autonomic dysfunction, and death. ${ }^{1}$ Benzodiazepines, especially diazepam, is considered as the mainstay of controlling muscle spasm, whereas the evidence with other sedatives such as phenobarbital and chlorpromazine is limited. ${ }^{6}$ Moreover, data from other limited number of studies suggested that antitoxins and antibiotics may improve the clinical outcome. ${ }^{7}$ However, the use of such drugs requires access to mechanical ventilation. Alternatively, the role of magnesium sulfate was evaluated by many authors. From the beginning of the last century, magnesium sulfate has become famous because of its attractive therapeutic effects. It can cause muscle relaxation and vasodilation, which encourages researchers to evaluate its effect on improved clinical outcome of tetanus. ${ }^{8}$ In 1985, James and Manson ${ }^{9}$ suggested that a continuous magnesium infusion might help to control blood pressure and heart rate. In 1997, Attygalle and Rodrigo ${ }^{10,11}$ also reported about reduced spasm, but when they replicated the same protocol in 2002, there they

* Address correspondence to Md Golam Hasnain, Centre for Clinical Epidemiology and Biostatistics (CCEB), School of Medicine and Public Health (SMPH), Faculty of Health and Medicine, The University of Newcastle, Callaghan, New South Wales 2308, Australia. E-mail: mdgolam.hasnain@uon.edu.au

†These authors contributed equally to this work. highlighted the needs of artificial ventilation. Therefore, being encouraged by the initial findings, some researchers moved toward controlled studies, and in 2006, Thwaites carried out a randomized double-blinded placebo control study, which failed to find out any significant difference in terms of ventilation support and survival. ${ }^{12}$ In 2008 , Osalusi evaluated the effect of magnesium against diazepam through a randomized controlled trial and obtained a reduced frequency of spasm in the second week of the trial compared with the control group. ${ }^{13}$ However, in 2011 another randomized study controlled by diazepam was conducted by Ali and failed to achieve any significant improvement in terms of spasms but gained improvement in terms of reducing ventilation support. ${ }^{14}$ In 2013, Kole published the result with a combination of magnesium and diazepam and was successful in reducing complications and hospital stay. ${ }^{15}$ However, all the studies highlighted the need of ventilation support. Countries that have not achieved elimination targets have limited resources and have also failed to achieve the expected immunization coverage. ${ }^{16}$ Furthermore, areas with low prevalence have limited capacity to manage the disease owing to poor support for the public health initiative and lack of physician familiarity. ${ }^{17}$ The treatment of this disease with ventilation support is very expensive and hard to afford.

To date, no study is reporting the use of combined therapy in resource-contrained settings where ventilators are not available. This case series aims to address that gap in knowledge by reporting on the treatment outcome of severe tetanus patients treated with both diazepam and magnesium sulfate simultaneously in a setting with no ventilation support.

\section{METHODS}

Study design, period, and setting. This is a retrospective case series of 42 patients with severe tetanus. These patients were treated during 2014-2015 at Surya Kanta Hospital, which is the infectious disease unit of Mymensingh Medical College Hospital (MMCH), Bangladesh. 
Study participants. A total of 45 patients were admitted during this period, of whom three died before initiating treatment and 42 received treatment based on the new treatment protocol (Table 1). There are no ventilation or surgical interventional facilities (e.g., tracheostomy) available in this hospital. The patients who were admitted here with severe tetanus could not gain admission in an intensive care unit (ICU) in a government health facility and lacked financial support to avail private health-care services.

Diagnosis, treatment, and outcome measurement. Patients were diagnosed with tetanus based on the clinical feature criteria of the World Health Organization guidelines, which require at least one of the following signs: trismus (inability to open the mouth), risus sardonicus (sustained spasm of the facial muscles), or painful muscular contractions. After diagnosis, grading of the disease was carried out using Ablett classification. The patients identified as severe tetanus patients were treated with the modified treatment protocol (Table 1), which includes diazepam, magnesium sulfate, immunotherapy, antibiotics, and intravenous fluid. We monitored the effects of increasing magnesium levels by recording inability to cough, suppression of patellar reflex, respiratory inadequacy, cardiovascular depression, and level of sedation. Treatment outcome was measured in terms of resolution of the disease, which was categorized as follows: recovered completely, recovered with sequela, and died. The patients were followed up from hospital admission to discharge.

Data collection and analysis. Data were collected from hospital records and verified by the investigators before data entry. Descriptive and analytical methods were used to evaluate the data using SPSS 22.0 (IBM Corp, Armonk, NY). Descriptive statistics included frequencies and proportions. Statistically significant differences between means were compared by parametric ( $t$ test and analysis of variance) or nonparametric (Mann-Whitney $U$ and Kruskal-Wallis) tests, where applicable. Comparison between proportions was assessed by either $x^{2}$ test or Fisher's exact test, where applicable. A multiple logistic regression was conducted to identify the odds of patients' clinical and treatment characteristics over the treatment outcome.

Ethical approval. Ethical approval was obtained from $\mathrm{MMCH}$ before data collection from the hospital and during analysis; all patient data were de-identified.

\section{RESULT}

The majority of the participants were male $(36,85.7 \%)$ and older than 18 years $(34,81 \%)$, and the median age was 30 years (interquartile range [IQR]: 20-45). Almost half of them $(18,42.9 \%)$ had no formal education, and the highest level of education was only up to the secondary level. Nearly all of them $(40,95.2 \%)$ were residents from urban areas. More than one-third $(15,35.7 \%)$ had a poor nutritional status, and the median body mass index was $19.35 \mathrm{~kg} / \mathrm{m}^{2}$ (IQR: 17.78-22.22). Only three $(7.1 \%)$ of them had previous tetanus immunization history, but none of them completed the national immunization schedule. All the patients presented to the hospital with lockjaw, convulsions, and respiratory distress. Most of them had lethargy or irritability, pain in the neck or back or abdomen, neck rigidity, fever, lower limb spasticity, and unconsciousness. Detailed distribution of clinical presentation is described in Table 2. Lower limb was the most common site for injury, followed by upper limb, ear picking, and ear injury. However, more than one-fifth of the cases failed to demonstrate any specific injury site. The median duration between wound acquisition and appearance of clinical symptoms was 12.5 (IQR: 4-90) days, and the median duration between appearance of clinical symptoms and diagnosis was 4 (IQR: 1-39) days. Table 2 shows the difference in patients' clinical and treatment information. The new treatment protocol was applied on 42 patients. Among them, 24 (57.1\%) recovered completely, six (14.3\%) recovered with sequela, and $12(28.6 \%)$ died. The hospital recorded the cause of death as cardiorespiratory failure for all the dead cases. Of those who

TABLE 1

Treatment provided to the patients

\begin{tabular}{|c|c|c|}
\hline Treatment $^{\star} \dagger$ & Aged 12 years or more & Aged less than 12 years \\
\hline \multirow[t]{4}{*}{$\begin{array}{l}\text { Magnesium sulfate } \\
\text { (intravenous) }\end{array}$} & $\begin{array}{l}\text { Twenty-four milligrams daily into three divided } \\
\text { doses }\end{array}$ & Twelve milligrams daily into three divided doses \\
\hline & $\begin{array}{l}\text { If no convulsion within } 12 \text { hours, then } 16 \mathrm{mg} \text { into two } \\
\text { divided doses }\end{array}$ & $\begin{array}{l}\text { If no convulsion within } 12 \text { hours, then } 8 \mathrm{mg} \text { into two } \\
\text { divided doses }\end{array}$ \\
\hline & $\begin{array}{l}\text { If no convulsion within } 24 \text { hours, then } 8 \mathrm{mg} \text { single } \\
\text { dose }\end{array}$ & $\begin{array}{l}\text { If no convulsion within } 24 \text { hours, then } 4 \text { mg single } \\
\text { dose }\end{array}$ \\
\hline & $\begin{array}{l}\text { Then if no convulsion state continues, then finally } \\
\text { stop }\end{array}$ & $\begin{array}{l}\text { Then if no convulsion state continues, then finally } \\
\text { stop }\end{array}$ \\
\hline \multirow{4}{*}{$\begin{array}{l}\text { Diazepam (intravenous } \\
\text { with infusion) }\end{array}$} & Sixty milligrams daily into three divided doses & Thirty milligrams daily into three divided doses \\
\hline & $\begin{array}{l}\text { If able to take food by mouth, then } 40 \mathrm{mg} \text { into two } \\
\text { divided doses for } 24 \text { hours }\end{array}$ & $\begin{array}{l}\text { If able to take food by mouth, then } 20 \mathrm{mg} \text { into two } \\
\text { divided doses for } 24 \text { hours }\end{array}$ \\
\hline & $\begin{array}{l}\text { If improvement continues, then } 20 \text { mg once daily for } \\
24 \text { hours }\end{array}$ & $\begin{array}{l}\text { If improvement continues, then } 10 \text { mg once daily for } \\
24 \text { hours }\end{array}$ \\
\hline & Finally, if improvement continues, then stop & Finally, if improvement continues, then stop \\
\hline \multirow[t]{2}{*}{ Immunotherapy (intramuscular) } & Human TIG 500 units & Human TIG 250 units \\
\hline & TT-containing vaccine, $0.5 \mathrm{~mL}$ & TT-containing vaccine, $0.5 \mathrm{~mL}$ \\
\hline \multirow[t]{2}{*}{ Antibiotics (intravenous) } & $\begin{array}{l}\text { Metronidazole intravenously } 500 \text { mg every } 6 \text { hours } \\
\text { for } 14 \text { days }\end{array}$ & $\begin{array}{l}\text { Metronidazole intravenously } 250 \text { mg every } 6 \text { hours } \\
\text { for } 14 \text { days }\end{array}$ \\
\hline & Ceftriaxone 2 gm intravenously daily for 14 days & One milligram intravenously daily for 14 days \\
\hline \multirow[t]{2}{*}{ Fluid (intravenous) } & One liter $5 \%$ dextrose aqua daily during hospital stay & 0.5 L $5 \%$ dextrose aqua daily up to hospital staying \\
\hline & $\begin{array}{l}\text { Two liter dextrose in normal saline daily during } \\
\text { hospital staying }\end{array}$ & $\begin{array}{l}\text { One liter dextrose in normal saline daily during } \\
\text { hospital stay }\end{array}$ \\
\hline
\end{tabular}


TABLE 2

Results of the comparison between the patients who survived and died during treatment

\begin{tabular}{|c|c|c|c|c|}
\hline \multirow[b]{2}{*}{ Patient characteristics } & \multirow[b]{2}{*}{ Total, $n=42$} & \multicolumn{3}{|c|}{ Group } \\
\hline & & Survived, $n=30$ & Died, $n=12$ & $P$ value \\
\hline \multicolumn{5}{|l|}{ Age in years } \\
\hline Median $\left(Q_{1}-Q_{3}\right)$ & $30(20-45)$ & $37.5(27-48)$ & $42.5(26-56)$ & 0.0462 \\
\hline \multicolumn{5}{|l|}{ Gender, $n(\%)$} \\
\hline $\begin{array}{l}\text { Male } \\
\text { Body mass index in } \mathrm{kg} / \mathrm{m}^{2}\end{array}$ & $36(85.7)$ & $24(80.00)$ & $12(100)$ & 0.159 \\
\hline Median $\left(Q_{1}-Q_{3}\right)$ & $19.35(17.78-22.22)$ & $20.35(17.78-23.11)$ & $18.89(16.97-20.68)$ & 0.2256 \\
\hline \multicolumn{5}{|l|}{ Clinical characteristics } \\
\hline \multicolumn{5}{|c|}{$\begin{array}{l}\text { Duration between wound and appearance } \\
\text { of symptoms in days }\end{array}$} \\
\hline Median $\left(Q_{1}-Q_{3}\right)$ & $12.5(4-90)$ & $17(7-25)$ & $8(6-16)$ & 0.2481 \\
\hline \multicolumn{5}{|c|}{$\begin{array}{l}\text { Duration between appearance of symptoms } \\
\text { and diagnosis in days }\end{array}$} \\
\hline Median $\left(Q_{1}-Q_{3}\right)$ & $4(1-39)$ & $4(2-7)$ & $4(2.5-6.5)$ & 0.8003 \\
\hline \multicolumn{5}{|l|}{ Route of entry } \\
\hline \multicolumn{5}{|l|}{ Upper limb } \\
\hline Yes & $7(16.67)$ & $5(16.67)$ & $2(16.67)$ & 1.00 \\
\hline \multicolumn{5}{|l|}{ Lower limb } \\
\hline Yes & $19(45.24)$ & $12(40.00)$ & $7(58.33)$ & 0.323 \\
\hline \multicolumn{5}{|l|}{ Ear } \\
\hline Yes & $1(2.38)$ & $1(3.33)$ & $00(00)$ & 1.00 \\
\hline \multicolumn{5}{|l|}{ Ear pick } \\
\hline Yes & $5(11.90)$ & $4(13.33)$ & $1(8.33)$ & 1.00 \\
\hline \multicolumn{5}{|l|}{ No causative factor } \\
\hline Yes & $10(23.81)$ & $8(26.67)$ & $2(16.67)$ & 0.696 \\
\hline \multicolumn{5}{|l|}{ Clinical symptoms } \\
\hline \multicolumn{5}{|l|}{ Lethargy/irritability } \\
\hline Yes & $40(95.24)$ & 28 (93.33) & $12(100)$ & 1.00 \\
\hline \multicolumn{5}{|l|}{ Pain in the neck/back/abdomen } \\
\hline Yes & $39(92.86)$ & $28(93.33)$ & $11(91.67)$ & 1.00 \\
\hline \multicolumn{5}{|l|}{ Neck rigidity } \\
\hline Yes & $38(90.48)$ & $26(86.67)$ & $12(100)$ & 0.308 \\
\hline \multicolumn{5}{|l|}{ Fever } \\
\hline Yes & $38(90.48)$ & $28(93.33)$ & $11(83.33)$ & 0.565 \\
\hline \multicolumn{5}{|l|}{ Lower limb spasticity } \\
\hline Yes & 36 (85.71) & $25(81.33)$ & $11(91.67)$ & 0.655 \\
\hline \multicolumn{5}{|l|}{ Unconsciousness } \\
\hline Yes & $34(80.94)$ & $24(80.00)$ & $10(80.33)$ & 1.00 \\
\hline \multicolumn{5}{|l|}{ Retention of urine } \\
\hline \multirow{2}{*}{\multicolumn{5}{|c|}{$\begin{array}{l}\text { Yes } \\
\text { Upper limb spasticity }\end{array}$}} \\
\hline & & & & \\
\hline Yes & $21(50)$ & $15(50)$ & $6(50)$ & 1.00 \\
\hline \multicolumn{5}{|l|}{ Rhisus sardonicus } \\
\hline Yes & $13(30.95)$ & $9(30.00)$ & $4(33.33)$ & 1.00 \\
\hline \multicolumn{5}{|l|}{ Opisthotonus } \\
\hline Yes & $6(14.29)$ & $5(16.67)$ & $1(8.33)$ & 0.655 \\
\hline
\end{tabular}

recovered with sequela, four needed mechanical support during walking, specially feeling weakness in any one of their legs, and two had visual impairment, specifically poor distant vision. No significant adverse event was recorded during the treatment period. Results from the logistic regression are shown in Table 3.

\section{DISCUSSION}

In resource-limited countries, it is a common occurrence for patients to not have access to specialized care such as ventilator support in hospitals. The patients presented in this case series are an accurate depiction of this scenario as they could not gain access to ventilation support in the public health-care system and could not afford access via the private health-care system. Although ventilator support is mentioned as a requirement in tetanus management guidelines, our results show an overall recovery of $71.4 \%$ with the modified treatment protocol that does not include any ventilation support.
Placing our results into the context of previous research is difficult as we have only one study on combination therapy from India that was supported by ventilation. ${ }^{15}$ So, according to us this is the first study that has evaluated the treatment of tetanus where ventilation facility was not available. However, the study from India which was a case series of 86 cases comparing retrospective data showed that combined treatment with magnesium sulfate and diazepam can decrease the duration of reflex spasm, ANS involvement, respiratory depression, duration of hospital stay, duration of ventilation support, and overall mortality. ${ }^{15}$ In context with the results of the previous study, this case series was used to report on the outcome of severe tetanus cases treated with the combination protocol in scenarios where ventilation support is unavailable.

Benzodiazepines are the standard therapy for controlling muscle spasms and have gained popularity because of its muscle relaxant, anticonvulsant, sedative, and anxiolytic effects, and for this purpose, the most popular option is 
TABLE 3

Results of the multivariable logistic regression

\begin{tabular}{|c|c|c|}
\hline & $\mathrm{OR}(95 \% \mathrm{Cl})^{*}$ & $P$ value \\
\hline \multicolumn{3}{|l|}{ Patient characteristics } \\
\hline Age in years & $1.0428(0.9990-1.0885)$ & 0.055 \\
\hline $\mathrm{BMl}$ in $\mathrm{kg} / \mathrm{m}^{2}$ & $0.8673(0.6958-1.0801)$ & 0.205 \\
\hline \multicolumn{3}{|l|}{ Clinical characteristics } \\
\hline Duration between wound and appearance of symptoms in days & $0.9674(0.9122-1.0260)$ & 0.269 \\
\hline Duration between appearance of symptoms and diagnosis in days & $0.9644(0.8525-1.0910)$ & 0.564 \\
\hline \multicolumn{3}{|l|}{ Route of entry } \\
\hline \multicolumn{3}{|l|}{ Upper limb } \\
\hline Yes & $1.00(0.1659-6.0275)$ & 1.00 \\
\hline \multicolumn{3}{|l|}{ Lower limb } \\
\hline Yes & $2.1(0.5388-8.1850)$ & 0.285 \\
\hline \multicolumn{3}{|l|}{ Ear pick } \\
\hline Yes & $0.5909(0.0591-5.9051)$ & 0.654 \\
\hline \multicolumn{3}{|l|}{ No causative factor } \\
\hline Yes & $0.55(0.0985-3.0726)$ & 0.496 \\
\hline \multicolumn{3}{|l|}{ Clinical symptoms } \\
\hline \multicolumn{3}{|l|}{ Pain in the neck/back/abdomen } \\
\hline Yes & $0.7857(0.0651-9.5692)$ & 0.850 \\
\hline \multicolumn{3}{|l|}{ Fever } \\
\hline Yes & $0.3571(0.0442-2.8838)$ & 0.334 \\
\hline \multicolumn{3}{|l|}{ Lower limb spasticity } \\
\hline Yes & $2.2(0.2295-21.1063)$ & 0.142 \\
\hline \multicolumn{3}{|l|}{ Unconsciousness } \\
\hline Yes & $1.25(0.2145-7.2811)$ & 0.804 \\
\hline \multicolumn{3}{|l|}{ Retention of urine } \\
\hline Yes & $0.7273(0.1710-3.0928)$ & 0.666 \\
\hline \multicolumn{3}{|l|}{ Upper limb spasticity } \\
\hline Yes & $1.00(0.2621-3.8149)$ & 1.00 \\
\hline \multicolumn{3}{|l|}{ Rhisus sardonicus } \\
\hline Yes & $1.1667(0.2787-4.8844)$ & 0.833 \\
\hline \multicolumn{3}{|l|}{ Opisthotonus } \\
\hline Yes & $0.4545(0.0474-4.3608)$ & 0.494 \\
\hline
\end{tabular}

* Adjusted for age, gender, and BMI.

diazepam, which is cheap and available in resource-limited countries. Many early studies established the role of diazepam as a useful agent in tetanus, and some of them proved its superiority over other sedatives. ${ }^{16,18,19}$ Benzodiazepines are long acting and dose adjusted with the clinical severity, sometimes requiring large doses. This large volume may create metabolic acidosis and can prolong recovery. ${ }^{10}$ On the other hand, magnesium sulfate is widely accepted for its efficacy on eclampsia which has anticonvulsant property also. ${ }^{20,21}$ Magnesium treatment to control tetanic spasms has been recorded in the medical literature for a long time. Many studies showed this treatment option as an effective one but did not recommend it as a sole therapy ${ }^{15,16}$ and also suggested the need for ventilation. In one of the important studies in 2006 by Thwates et al., a randomized controlled trial of 190 patients, conventional treatment (including diazepam or midazolam) with/without additional magnesium failed to show benefit in severe tetanus. Our case series results further reaffirm that this protocol has a positive role in recovery from severe tetanus, with $57 \%$ recovering completely and $14 \%$ recovering with sequela in a situation without ventilation. However, despite having a positive indication, this study has several limitations. This is a retrospective study which was conducted through hospital data collection; therefore, we have missed some of the important information, for example, period of hypoxia, using toxic drugs, and others. Moreover, this study is just reporting a case series of 42 patients; therefore, to reach a complete solution using this study is challenging.
Tetanus continues to remain a significant and preventable cause of death globally, especially in low- and middle-income countries. However, because of its scattered prevalence, it is difficult to conduct large trials to test the efficacy and safety of modified treatment protocols, such as the one suggested in this study. The results gathered during this case series provide a sustainable, low-cost, and effective solution for the management of severe tetanus in resource-constrained settings where ICUs are unavailable. As a result, further research can be conducted on the basis of these results to further consolidate the findings.

Received February 28, 2018. Accepted for publication July 12, 2018. Published online September 10, 2018.

Acknowledgments: The American Society of Tropical Medicine and Hygiene (ASTMH) assisted with publication expenses.

Ethical considerations: De-identified patient data were collected after obtaining the respective institution's approval.

Authors' addresses: Md Golam Hasnain, Centre for Clinical Epidemiology and Biostatistics (CCEB), School of Medicine and Public Health, Faculty of Health and Medicine, The University of Newcastle (UoN), Newcastle, Australia, E-mail: mdgolam.hasnain@uon.edu.au. Shomik Maruf, Nutrition and Clinical Service Division (NCSD), International Centre for Diarrhoeal Disease Research, Bangladesh (icddr,b), Dhaka, Bangladesh, E-mail: shomik_stj@yahoo.com. Proggananda Nath and Md Nasir Uddin Ahmed, Infection and Tropical Medicine, Mymensingh Medical College Hospital (MMCH), Mymensingh, Bangladesh, E-mails: progganath@yahoo.com and brignasir584@gmail.com. Azim Anuwarul, Diarrhoeal Diseases, Mymensingh Medical College and Hospital (MMCH), Mymensingh, 
Bangladesh, E-mail: azimanwarul@gmail.com. Iqbal Hossain Chowdhury, Department of Intensive Care Unit, Bangabondhu Sheikh Mujib Medical University (BSMMU), Mymensingh, Bangladesh, E-mail: Iqbal.hossain.56@gmail.com. Ariful Basher, Critical Care Medicine (CCM), Bangabondhu Sheikh Mujib Medical University (BSMMU), Mymensingh, Bangladesh, E-mail: ariful.dr@ gmail.com.

\section{REFERENCES}

1. Chalya PL, Mabula JB, Dass RM, Mbelenge N, Mshana SE, Gilyoma JM, 2011. Ten-year experiences with tetanus at a tertiary hospital in northwestern Tanzania: a retrospective review of 102 cases. World J Emerg Surg 6: 20.

2. Brauner JS, Vieira SR, Bleck TP, 2002. Changes in severe accidental tetanus mortality in the ICU during two decades in Brazil. Intensive Care Med 28: 930-935.

3. Joshi S, Agarwal B, Malla G, Karmacharya B, 2007. Complete elimination of tetanus is still elusive in developing countries: a review of adult tetanus cases from referral hospital in eastern Nepal. Kathmandu Univ Med J 5: 378-381.

4. Chukwubike OA, God'spower AE, 2009. A 10-year review of outcome of management of tetanus in adults at a Nigerian tertiary hospital. Ann Afr Med 8: 168-172.

5. Kyu HH, Mumford JE, Stanaway JD, Barber RM, Hancock JR, Vos T, Murray C, Naghavi M, 2017. Mortality from tetanus between 1990 and 2015: findings from the global burden of disease study. BMC Public Health 17: 179.

6. Okoromah CN, Lesi FE, 2004. Diazepam for treating tetanus. Cochrane Database Syst Rev 1: CD003954.

7. Yen LM et al., 1997. Management of Tetanus: A Comparison of Penicillin and Metronidazole. Symposium of Antimicrobial Resistance in Southern Viet Nam, Ho Chi Minh City, Vietnam.

8. Altura BM, Altura BT, 1981. Magnesium ions and contraction of vascular smooth muscles: relationship to some vascular diseases. Fed Proc 40: 2672-2679.

9. James MF, Manson ED, 1985. The use of magnesium sulphate infusions in the management of very severe tetanus. Intensive Care Med 11: 5-12.
10. Attygalle D, Rodrigo N, 1997. Magnesium sulphate for control of spasms in severe tetanus. Can we avoid sedation and artificial ventilation? Anaesthesia 52: 956-962.

11. Attygalle $D$, Rodrigo N, 2002. Magnesium as first line therapy in the management of tetanus: a prospective study of 40 patients. Anaesthesia 57: 811-817.

12. Thwaites CL, Yen LM, Loan HT, Thuy TTD, Thwaites GE, Stepniewska K, Soni N, White NJ, Farra JJ, 2006. Magnesium sulphate for treatment of severe tetanus: a randomised controlled trial. Lancet 368: 1436-1443.

13. Osalusi BS, Ogun SA, Ogunniyi A, Kolapo KO, 2008. Comparison of the efficacy of magnesium sulphate and diazepam in the control of tetanus spasms. Sci Res Essays 3: 571-576.

14. Ali G, Kamal M, Khan AN, 2011. Comparison of the efficacy of magnesium sulphate and diazepam in the control of tetanus spasm. J Postgrad Med Inst 25: 106-110.

15. Kole AK, Roy R, Kar SS, Kole DC, 2013. Experience of use of magnesium sulfate in the treatment of tetanus in a tertiary referral Infectious Disease Hospital, Kolkata, India. Ann Trop Med Public Health 6: 456-459.

16. WHO Vaccine-Preventable Disease Monitoring System, 2016. Global Summary. Available at: http://www.who.int/immunization/ monitoring_surveillance/data/en/. Accessed December 12, 2017.

17. Chaudhry R, Dhawan B, Mohanty S, Dey AB, 2001. Tetanus in the elderly: a forgotten illness. Lancet 1805: 357.

18. Norredam K, Hainau B, 1970. Treatment of tetanus in tropical Africa: a comparison between a barbiturate and diazepam in the treatment of non-neonatal tetanus. Ann Soc Belges Med Trop Parasitol Mycol 50: 239-246.

19. Joseph A, Pulimood BM, 1978. Use of diazepam in tetanus-a comparative study. Indian J Med Res 68: 489-491.

20. Karanikolas M, Velissaris D, Marangos M, Karamouzos V, Fligou F, Filos KS, 2010. Prolonged high-dose intravenous magnesium therapy for severe tetanus in the intensive care unit: a case series. J Med Case Rep 4: 100.

21. Mathew PJ, Samra T, Wig J, 2010. Magnesium sulphate for treatment of tetanus in adults. Anaesth Intensive Care 38: 185-189. 